\title{
STRATEGI MENINGKATKAN JUMLAH PENGUNJUNG THEME PARK (KASUS: WORLD OF WONDER - CITRA RAYA)
}

\author{
Ayu Nurazizah Hertadi ${ }^{1)}$, Priyendiswara Agustina Bela ${ }^{2)}$, B. Irwan Wipranata ${ }^{3)}$
}

1)Program Studi S1 PWK, Fakultas Teknik, Universitas Tarumanagara, ayunurazizah2106@gmail.com

2)Program Studi S1 PWK, Fakultas Teknik, Universitas Tarumanagara, hedy.agustina@gmail.com

3)Program Studi S1 PWK, Fakultas Teknik, Universitas Tarumanagara, irwan_wipranata@yahoo.co.uk

Masuk: 11-08-2020, revisi: 07-09-2020, diterima untuk diterbitkan: 25-09-2020

\begin{abstract}
Abstrak
Citra Raya World of Wonder merupakan proyek seluas 4,3 hektar dari developer ternama Ciputra Grup yang bekerjasama dengan PT. Carnival Wisata Sejahtera yang merupakan anak usaha dari PT. Bunga Wangsa Sejati yang juga merupakan pengembang dari Jatim Park, Batu Night Spectaculer di Malang yang menyediakan berbagai wahana permainan di area Citra Raya World of Wonder, yang telah beroperasi sejak tahun 2012. Theme Park Citra Raya World of Wonder merupakan salah satu lokasi yang diharapkan dapat menjadi salah satu destinasi wisata sebagai kota yang menyajikan pusat-pusat rekreasi, edukasi, bisnis, dan kuliner. Pada saat ini terdapat 4 pembagian wahana serta fasilitas penunjang yang ada di objek studi. Penelitian ini bertujuan untuk mengetahui potensi dan masalah yang terdapat di Citra Raya World of Wonder, untuk mengetahui fakor-faktor yang menjadi penyebab menurunnya jumlah pengunjung, mengetahui kinerja ketercapaian jumlah pengunjung dan memberikan usulan berupa strategi yang bertujuan untuk meningkatkan jumlah pengunjung guna meningkatkan minat masyarakat. Pengumpulan data dalam penelitian ini dilakukan dengan cara survei lapangan, wawancara dengan pengelola, penyebaran kuesioner kepada pengunjung, dokumentasi serta studi pustaka. Dari hasil penelitian ini penulis melakukan analisis lokasi, analisis bangunan, analisis daya dukung kawasan, analisis ketercapaian target jumlah pengunjung, analisis best practice dan analisis persepsi pengunjung. Analisis ini akan diolah oleh penulis, hasil tersebut akan digunakan untuk mengurangi masalah dan juga meningkatkan potensi dalam bentuk suatu usulan strategi yang bertujuan untuk meningkatkan jumlah pengunjung sehingga mencapai target daya tampung.
\end{abstract}

Kata kunci: pengunjung; strategi; taman bertema

\begin{abstract}
Citra Raya World of Wonder is a big project of 4.3 hectares from a well-known developer Ciputra Group. This developer cooperates with PT Carnival Wisata Sejahtera, a subsidiary of PT Bunga Wangsa Sejati, who is a developer of Jatim Park and Batu Night Spectacular in Malang which provide amusement rides in Citra Raya World of Wonder area and has been operating since 2012. Citra Raya World of Wonder Theme Park is one of the locations expected to be a tourism destination as a city that provides recreation, education, business, and culinary centers. There were 4 sections of rides and supporting facilities in the study object. This study aimed to discover the presence of Citra Raya World of Wonder's potential and problems, understand factors affecting the decreased number of visitors, understand visitor achievement performance, and suggest strategies to enhance the number of visitors to attract people's interest. The data collection conducted by field survey, management interview, visitor questionnaire, documentation, and literature study. The study result processed through several analyses, i.e., location, building, visitor target achievement, best practice, and perception. These analyses were processed, and the result used to answer the problems and improve the potential in the form of strategies suggested to enhance the number of visitors to achieve the target.
\end{abstract}

Keywords: strategy; themepark; visitor 


\section{PENDAHULUAN}

\section{Latar Belakang}

Di Indonesia saat ini Theme Park yang merupakan wisata buatan dengan konsep wahana hiburan bukanlah satu hal yang baru, dimana di setiap tempat daerah terutama kota-kota besar di Indonesia telah banyak dibangun ataupun sudah lama dibangun sebagai contoh "Taman Impian Jaya Ancol" yang sudah terkenal dan melekat ditelinga khalayak masyarakat Indonesia sebagai satu wahana bermain yang menarik untuik dikunjungi. World of Wonder Citra Raya merupakan Theme Park berbasis sebagai wahana wisata keluarga yang berada di Citra Raya, Kabupaten Tangerang, tepatnya beralamat di Jalan Ecopolis Boulevard Mekar Bakti Panongan, Mekar Bakti, Kec. Panongan, Kabupaten Tangerang, Banten.

Citra Raya World of Wonder merupakan proyek besar seluas 4,3 hektar dari developer ternama Ciputra Grup, Citra Raya World of Wonder telah beroperasi sejak tahun 2012. Citra Raya World of Wonder Theme Park merupakan salah satu lokasi yang diharapkan dapat menjadi salah satu destinasi wisata sebagai kota yang menyajikan pusat-pusat rekreasi, edukasi, bisnis, dan kuliner.

Dibandingkan dengan Theme Park di Indonesia lainya Citra Raya World of Wonder tergolong yang memiliki sepi pengunjung dimana daya tampung Citra Raya World of Wonder ialah sebanyak 6000 pengunjung, tetapi pada bulan januari 2019 jumlah pengunjung Citra Raya World of Wonder hanya 9000 pengunjung dalam satu bulan dimana jika dirata-ratakan jumlah pengunjung perhari di Citra Raya World of Wonder hanya mencapai 300 pengunjung. Sedangkan pada tahun 2016 jumlah pengunjung perhari bisa mencapai 1500 pengunjung.

Pada studi ini akan dibahas mengenai faktor-faktor penyebab menurunnya jumlah pengunjung di Citra Raya World of Wonder. Hasil tersebut akan digunakan untuk mengurangi masalah dan juga meningkatkan potensi dalam bentuk suatu usulan strategi yang bertujuan untuk meningkatkan jumlah pengunjung sehingga mencapai target daya tampung.

\section{Rumusan Permasalahan}

Jumlah pengunjung di World of Wonder Citra Raya setiap tahunnya mengalami penurunan dimana pada tahun 2012 jumlah pengunjung mencapai daya tampung maksimal, sedangkan saat ini jumlah pengunjung harian belum mencapai $10 \%$ dari daya tampung.

\section{Tujuan}

Tujuan yang ingin dicapai pada penelitian ini, yaitu untuk mengetahui potensi dan masalah yang terdapat di Citra Raya World of Wonder, untuk mengetahui fakor-faktor yang menjadi penyebab menurunnya jumlah pengunjung, mengetahui kinerja ketercapaian jumlah pengunjung dan memberikan usulan berupa strategi yang bertujuan untuk meningkatkan jumlah pengunjung sehingga mencapai target daya tampung.

\section{KAJIAN LITERATUR}

\section{Theme Park}

Theme Park merupakan atraksi yang ditujukan untuk rekreasi yang ditekankan pada fantasi dan imajinasi yang dibuat dengan pertimbangan khusus, seperti Disney World (dalam skala besar), Water Activity Park (dalam skala kecil). Istilah Theme Park memiliki arti yang lebih luas bukan sekedar 'taman bertema'. Michael Sorkin dalam pengantarnya di buku "A Variation on Theme Park: The New American City and the End of Public Space", mendefinisikan tentang Theme Park sebagai 'dunia' atau tempat yang memiliki ciri antara lain tidak terikat pada geografi tertentu, lingkungan yang terkontrol dan teramati, memberikan stimulasi tanpa henti (Sorkin, Michael; 1992; ix). 
Theme Park menurut IAAPA (Association of Amusement Parks and Attractions, berisi berbagai hiburan, makanan minuman, toko-toko dan lingkungan yang dirancang sesuai dengan tema yang dibuat. Kemudian mereka akan menambahkan bahwa Theme Park adalah sebuah taman hiburan yang bertema atraksi, baik itu makanan, kostum, hiburan, toko ritel, dan atau wahana. Tema yang menjadi bagian utama dari pengalaman pengunjung yang dipilih ketika taman direncanakan untuk memberikan focus untuk desain, pengembangan, dan pengoperasian dari taman tersebut.

\section{Pengunjung}

Pengunjung merupakan salah satu komponen pariwisata. Terdapat beberapa kelompok pengunjung sesuai karakteristik dan pola kunjungannya (Phillips \& Pittman, 2009). Berikut ini merupakan karakteristik pengunjung, yaitu :

a. Jenis Kelamin

b. Usia

c. Tempat tinngal

d. Status pekerjaan

e. Pendapatan yang diterima dalam satu bulan

Sedangkan untuk pola kunjungan yaitu :

a. Tujuan melakukan kegiatan wisata

b. Frekuensi kunjungan

c. Teman dalam melakukan kunjungan wisata (individu atau berkelompok)

d. Waktu berkunjung

e. Pengeluaran selama berkunjung

Selain itu pentingnya memperhatikan daya dukung lingkungan dalam pengelolaan. Dengan menggunakan daya dukung rekreasi yang optimal. Hal ini menunjukkan jumlah penggunaan pada sebuah tempat rekreasi yang dapat melindungi tempat tersebut untuk sumber daya kepuasan manusia. (Douglass, 1982).

\section{Strategi}

Menurut David (2006:17) strategi merupakan alat untuk mencapai tujuan jangka panjang. Strategi juga dapat diartikan sebagai tindakan potensial yang membutuhkan keputusan manajemen tingkat atas dan sumber daya perusahaan dalam jumlah yang besar. Selain itu, strategi dapat mempengaruhi kemakmuran perusahaan dalam jangka panjang, khusus untuk lima tahun dan beriorientasi kemasa depan. Strategi memiliki konsekuensi yang multifungsi dan multidimensi serta perlu mempertimbangkan faktor-faktor internal yang dihadapi oleh perusahaan.

Sedangkan menurut Milles dan Snow et,.al dalam Kuncoro (2005: 88-89) mengungkapkan bahwa keberhasilan suatu organisasi dalam menggunakan strategi untuk bisa beradaptasi dengan lingkungan pesaingnya dapat melalui beberapa strategi diantaranya yaitu:

a. Strategi Prospektor (Prospector) yaitu strategi yang mengutamakan pada keberhasilan organisasi dalam berinovasi, selalu menciptakan produk baru dan kesempatan pasar yang baru.

b. Strategi bertahan (Defender) yaitu perusahaan dengan strategi bertahan biasanya mementingkan stabilitas pasar yang menjadi targetnya

c. Strategi Penganalisis (Analyzer) yaitu merupakan strategi analisis dan imitasi. Organisasi yang menggunkan strategi ini akan menganalisis ide bisnis baru sebelum organisasi untuk memasuki bisnis tersebut.

d. Strategi reaktor yaitu organisasi yang bereaksi terhadap perubahan lingkungan dan membuat suatu perubahan hanya apabila terdapat tekanan dari lingkunganya yang memaksa organisasi tersebut untuk berubah 


\section{Pemasaran}

Pemasaran adalah proses perencanaan dan pelaksanaan konsepsi, penetapan harga, promosi dan distribusi gagasan, barang dan jasa untuk menciptakan pertukaran yang memuaskan tujuan individual dan operasional. (American Marketing Association, 1985).

\section{Daya Tarik Wisata}

Daya tarik wisata merupakan segala sesuatu hal yang menjadi daya tarik bagi seseorang untuk mengunjungi suatu daerah (Yoeti,1985) sedangkan jika menurut Nyoman S. Pendit (1994) menyatakan bahwa daya tarik wisata merupakan sebagai segala sesuatu yang menarik dan bernilai untuk dikunjungi. Menurut pada ahli dapat disimpulkan bahwa daya tarik wisata merupakan sesuatu yang bernilai sehingga hal ini dapat memikat orang untuk datang dan melihat ke lokasi tersebut.

\section{METODE}

Pada penelitian ini lokasi yang menjadi objek studi berada di Theme Park Citra Raya World of Wonder yang berlokasi di kawasan Citra Raya, Kabupaten Tangerang. Luas wilayah yang diteliti sebesar 4,3 hektar yang merupakan luas dari objek studi. Batas lokasi objek wisata Citra Raya World of Wonder, adalah: (1) Sebelah Barat: Jalan Ecopolis Citra Raya; (2) Sebelah Utara: Jalan Citra Raya Utama; (3) Sebelah Timur: Citra Raya Water World; (4) Sebelah Selatan: Jalan Ecopolis Citra Raya.

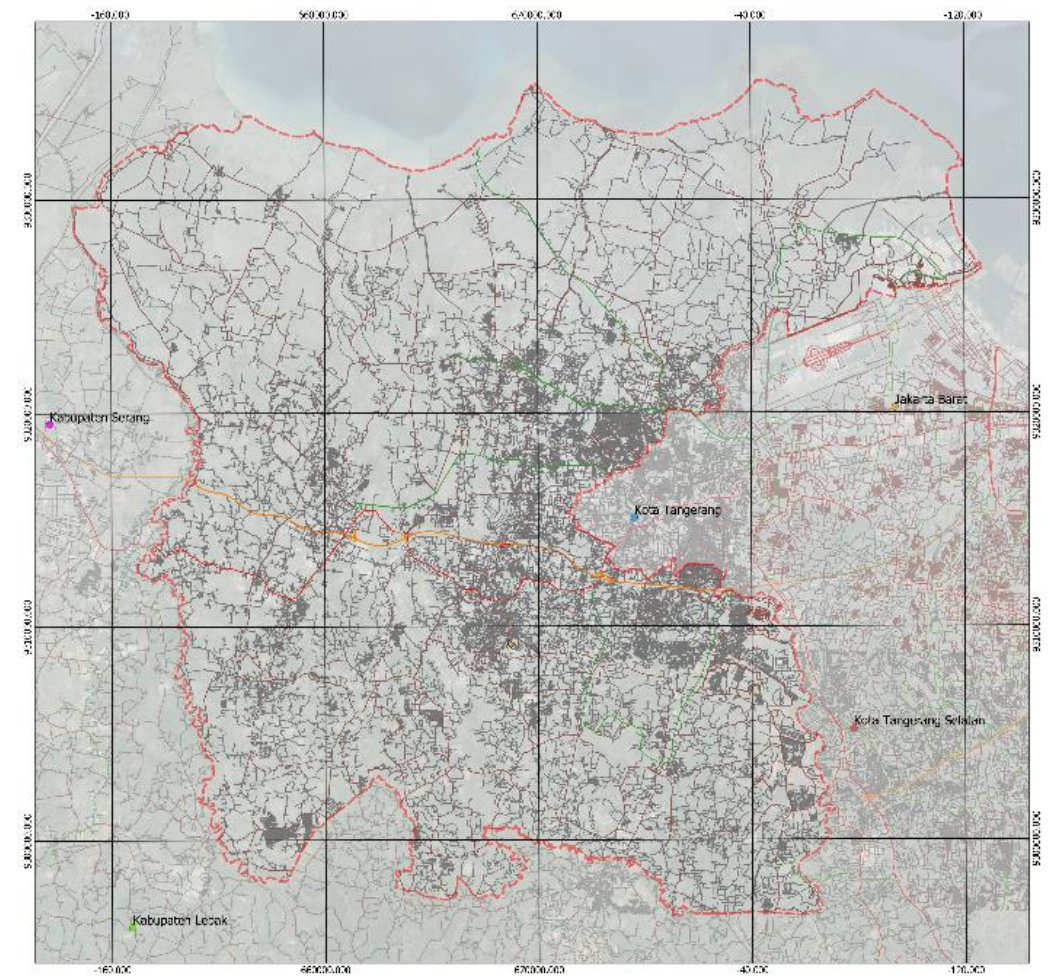

Gambar 1. Letak Lokasi Objek Studi Terhadap Kabupaten Tangerang Sumber: Penulis, 2020 


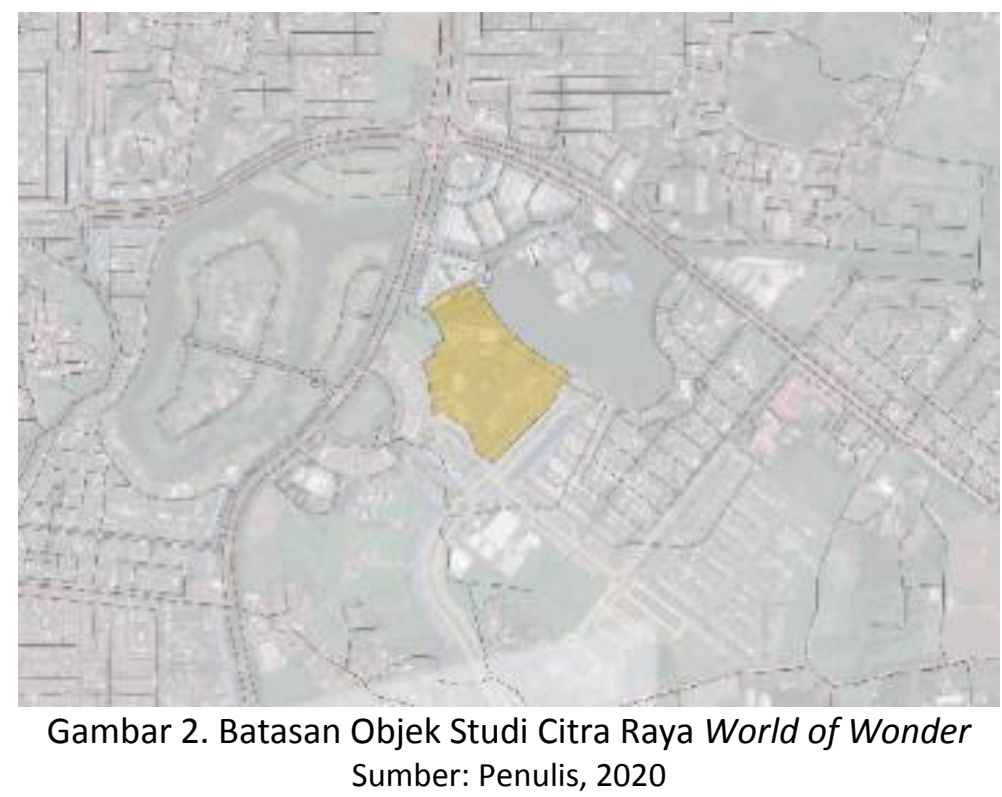

Pada proses penelitian ini terdapat data yang dibagi menjadi dua yaitu data primer maupun data sekunder, dimana pada data primer penulis memperoleh data dengan secara langsung kelapangan metode yang dilakukan diantaranya survey lapangan untuk mengetahui kondisi eksisting, wawancara dengan pihak pengelola untuk mengetahui profil Citra Raya World of Wonder, penyebaran kuesioner kepada para pengunjung Citra Raya World of Wonder untuk mengetahui persepsi dan dokumentasi. Sedangkan, pada data sekunder penulis memperoleh data melalui instansi terkait seperti BPS, dan pengelola Citra Raya World of Wonder data ini didapatkan dengan memberikan surat permohonan data kepada instansi yang terkait. Pada penelitian ini penulis melakukan 6 analisis yang akan diolah untuk mengetahui hasil akhir, diantara nya adalah:

a. Analisis Lokasi; Analisis ini bertujuan untuk mengetahui potensi masalah lokasi serta karakteristik lokasi di sekitar Citra Raya World of Wonder dengan mengetahui Aksesibilitas, Jaringan Transportasi Umum dan Penggunaan Lahan di lingkungan sekitar. Menggunakan alat analisis deskriptif dan SWOT.

b. Analisis Bangunan; Analisis ini bertujuan untuk mengetahui konsidi eksisting bangunan dan fasilitas yang ada di Citra Raya World of Wonder. Menggunakan alat analisis deskriptif dan SWOT

c. Analisis Daya Dukung Kawasan; Analisis ini bertujuan untuk melihat kerapatan dan jenis vegetasi pada objek studi agar mengetahui potensi keberlanjutan kedepannya. Analisis daya dukung kawasan bertujuan untuk mengetahui daya tampung objek studi setiap harinya berdasarkan kondisi luasan eksisting, jumlah pengunjung dan durasi kunjungan. Menggunakan alat analisis deskriptif dan SWOT.

d. Analisis Ketercapaian Target Jumlah Pengunjung; Analisis ini bertujuan untuk melihat Kinerja Ketercapaian jumlah pengunjung Citra Raya World of Wonder, melihat apa saja yang telah dilakukan pihak pengelola seperti event apa yang telah dilakukan dan promosi apa yang ditawarkan.

e. Analisis Best Practice; Analisis ini menggunakan alat analisis benchmarking, Benchmarking yang merupakan suatu proses yang biasa digunakan dalam manajemen atau pada umumnya disebut manajemen strategis, dimana suatu unit atau bagian atau organisasi lain yang sejenis baik secara internal maupun eksternal.

f. Analisis Persepsi Pengunjung; Analisis ini bertujuan untuk memperoleh karakteristik pengunjung dan kunjungan serta tanggapan dan penilaian pengunjung terhadap kondisi kawasan dan kualitas di Citra Raya World of Wonder. Selain itu, untuk mengatahui tingkat dari kepeningan dan kepuasan pada lokasi dan aksesibilitas, fasilitas umum, fasilitas wisata 
dan pekerja. Pada analisis ini menggunakan alat analisis deskriptif dan menggunakan metode Important Perfomance Analysis (IPA) yang bertujuan untuk mengukur hubungan antara konsumen dan prioritas peningkatan kualitas/jasa yang dikenal sebagai quadrant analysis.

\section{DISKUSI DAN HASIL}

Citra Raya World of Wonder merupakan Theme Park berbasis sebagai wahana wisata keluarga yang berada di Citra Raya, Kabupaten Tangerang. Citra Raya World of Wonder merupakan proyek besar seluas 4,3 Ha dari developer ternama Ciputra Grup bekerjasama dengan PT. Carnival Wisata Sejahtara anak usaha PT. Bunga Wangsa Sejati yang juga merupakan pengembang Jatim Park, Batu Night Spectaculer di Malang. Citra Raya World of Wonder merupakan salah satu lokasi yang diharapkan dapat menjadi salah satu destinasi baru sebagai kota yang menyajikan berbagai pusat- pusat rekreasi, edukasi, bisnis, kuliner yang telah diresmikan pada Tahun 2012.

Aksesibilitas menuju lokasi objek studi dirasa cukup memiliki akses yang baik. Ada beberapa opsi akses untuk pencapaian menuju Kawasan Citra Raya bisa ditempuh dari Tol Jakarta - Merak, keluar di pintu tol Bitung $(9 \mathrm{~km})$ atau dari Tol Jakarta - Merak, keluar di pintu tol Cikupa $(7 \mathrm{~km})$. Jalan ini menghubungkan dengan jalan arteri Jl. Raya Serang kemudian untuk pencapaian menuju objek studi dihubungkan melalu Jl. Citra Raya Boulevard. Jarak lokasi objek studi ke jalan arteri Jl. Raya Serang sekitar $3 \mathrm{Km}$, dengan waktu tempuh kurang lebih 10 menit. Kondisi jalan merupakan kondisi jalan yang baik dengan ROW $42 \mathrm{~m}$ dua arah dengan median 5 meter dan masing-masing arah memiliki 3 lajur dan 1 jalur sepeda.

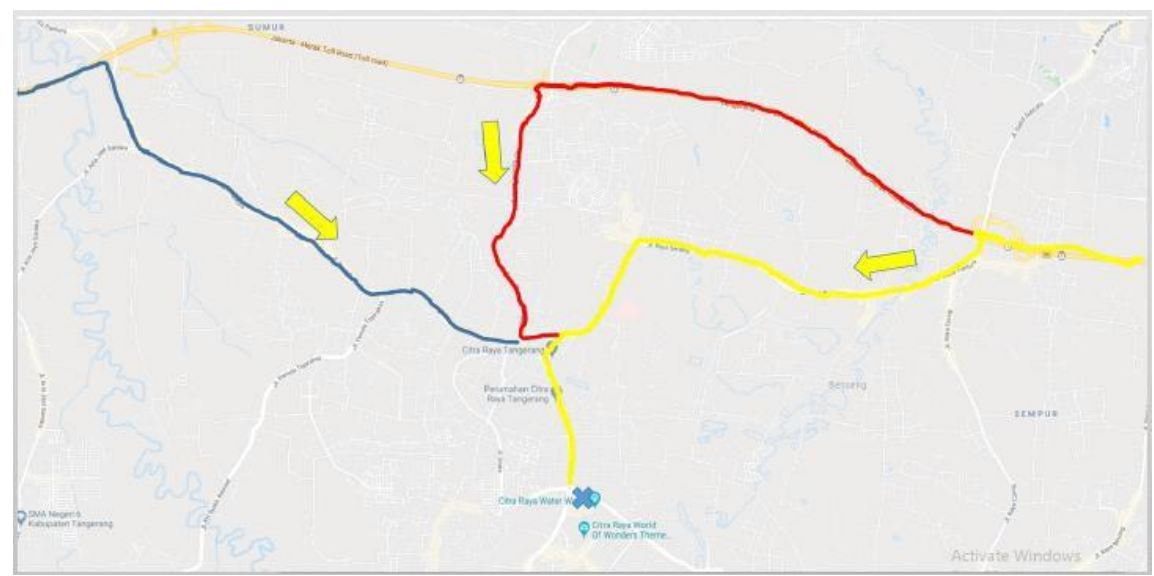

Gambar 3. Peta Aksesibilitas menuju Citra Raya World of Wonder Sumber: Google Maps dan Penulis, 2020

Tabel 1. Akses Menuju Citra Raya World of Wonder

\begin{tabular}{cclc}
\hline No & Lokasi Asal & \multicolumn{1}{c}{ Akses } & Keterangan \\
\hline 1 & Jakarta & Tol Jakarta - Merak (keluar pintu tol Bitung) - & Jarak Tempuh 35km Waktu \\
& Jlternatif 1 & $\begin{array}{c}\text { Jan Raya Serang - Jalan Boulevard Citra } \\
\text { Raya }\end{array}$ & Tempuh 1jam \\
& Jakarta & Tol Jakarta - Merak (keluar pintu tol Cikupa) - & Jarak Tempuh 40 km Waktu \\
& Alternatif 2 & $\begin{array}{l}\text { Jalan Raya Otonom Cikupa - Jalan Raya } \\
\text { Serang - Jalan Boulevard Citra Raya }\end{array}$ & Tempuh 1 \\
& Kota Tangerang 20 menit \\
\hline 3 & Selatan & Tol Tangerang - Merak (keluar pintu tol & Jarak Tempuh 20 km Waktu \\
& Bitung) - Jalan Raya Serang - Jalan Boulevard & Tempuh 31 menit \\
& Citra & \\
\hline 4 & Serang & Tol Tangerang - Merak (keluar pintu tol & Jarak Tempuh 52 km Waktu \\
& & Cikupa) - Jalan Raya Otonom Cikupa - Jalan & Tempuh 1 jam \\
& Raya Serang - Jalan Boulevard Citra Raya &
\end{tabular}


Citra Raya World of Wonder memiliki berbagai macam wahana, dimana wahana dibagi menjadi 4 bagian. Wahana keluarga, wahana edukasi dan sains, wahana anak-anak dan wahana miniature 7 keajaiban dunia. Berikut merupakan jenis wahana yang ditawarkan oleh Citra Raya World of Wonder, antara lain seperti pada Tabel 2 di bawah ini.

Tabel 2. Daftar Wahana Permainan Berdasarkan Pengelompokan Wahana

\begin{tabular}{|c|c|c|}
\hline No & Jenis Wahana & Permainan \\
\hline 1 & Wahana Keluarga & $\begin{array}{l}\text { Taman Dongeng, Virtual Ride, Taman Selfie, Lika Liku, Cangkir Putar, } \\
\text { Pemburu Dino, Jelajah Rimba, Taman Air, Rumah Angker, Techno } \\
\text { Fly, Kebat Kebit, Paralayang, Cinema Parthenon 4D, Galeri Ilusi, } \\
\text { Kapal Bajak Laut, Menara Outbond, Adventure Waterbond, Keliling } \\
\text { dunia, Gasing Alexandria, Sepeda Udara, Kincir Jurasic }\end{array}$ \\
\hline 2 & Wahana Edukasi dan Sains & $\begin{array}{l}\text { Taman Satwa, Kolam Tembak, Museum Satwa, Biologi, Planetarium, } \\
\text { Fisika }\end{array}$ \\
\hline 3 & Wahana Anak & $\begin{array}{l}\text { Outdoor Playground, Taman Lalu Lintas, Istana Ceria, Mobil } \\
\text { Gadiator, Perahu Liberty, Katak Kejut, Kuda Ria, Ayunan Kaisar }\end{array}$ \\
\hline 4 & Wahana 7 Keajaiban Dunia & $\begin{array}{l}\text { Menara Pisa, Istana Parthenon, Sphinx, San Fransisco, Candi } \\
\text { Borobudur, Tembok Cina, Piramid }\end{array}$ \\
\hline
\end{tabular}

Sumber: Hasil olahan penulis, 2020

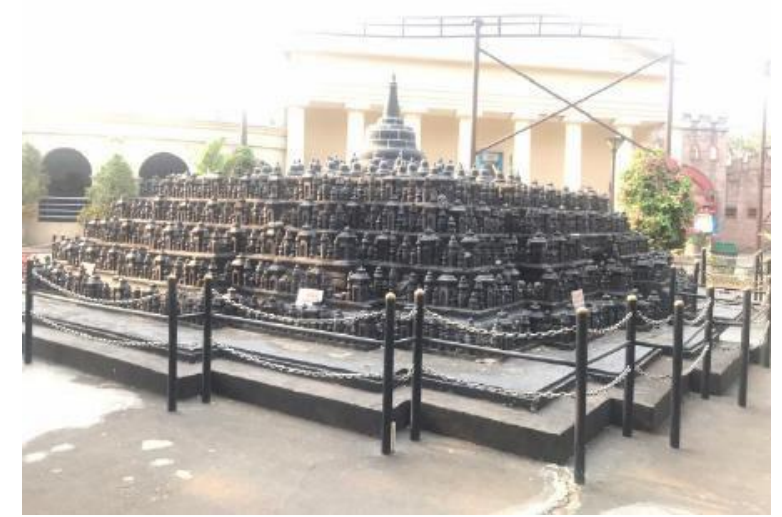

Gambar 4. Wahana 7 Keajaiban Dunia Sumber: Survey Lapangan, 2019

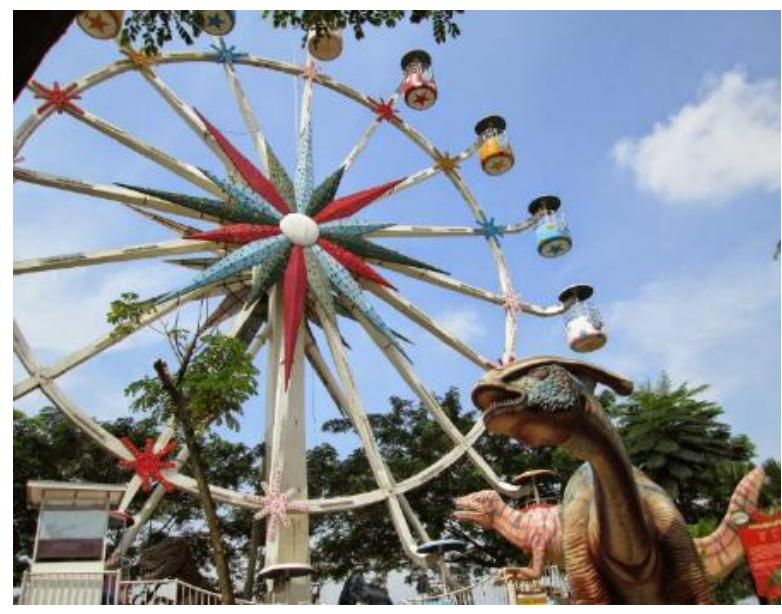

Gambar 5. Wahana Keluarga

Sumber: Google.com, 2020 


\section{Analisis Lokasi dan Bangunan}

Lokasi objek studi memiliki potensi yang cukup baik karena memiliki akses dari berbagai daerah, tetapi hal ini sangat disayangkan karena masih kurangnya transportasi umum (kecuali transportasi online) yang melewati Citra Raya World of Wonder dikarenakan transportasi umum hanya tersedia sekitar 2,3km dari kawasan objek studi tersebut. Terdapat masalah mengenai lokasi objek studi dimana lokasi citra raya World of Wonder berada pada zona permukiman kepadatan sedang. Jika dilihat dengan keadaan eksisting, kawasan objek studi tidak sesuai dengan RTRW. Kondisi eksisting bangunan dan fasilitas penunjang yag ada di Citra Raya World of Wonder sudah cukup baik namun ada saja wahana yang kurang terawat sehingga kurang diminati pengunjung serta peletakan fasilitas yang kurang terlihat keberadaanya dan minimnya papan petunjuk arah sehingga sedikit menyulitkan para pengunjung.

\section{Analisis Daya Dukung Kawasan}

Pada bab analisis daya dukung kawasan setelah dilakukan perhitungan menggunakan rumus Doglass diharapkan jumlah pengunjung minimal ialah 255 orang/hari sedangkan jumlah maksimal pengunjung ialah 956 orang/hari agar jumlah pengunjung yang datang tidak berlebihan dan menyebabkan kerusakan kawasan wisata. Selain daya dukung, terdapat pula hal menarik yang ada pada objek studi. Hal unik yang dapat dijual kepada pengunjung diberi nama USP. USP yang dimaksud merupakan suatu hal yang dapat membedakan produk apabila dibandingkan dengan produk yang lain (dalam hal ini objek studi).

\section{Analisis Ketercapaian Target Jumlah Pengunjung}

\section{Jumlah Pengunjung}

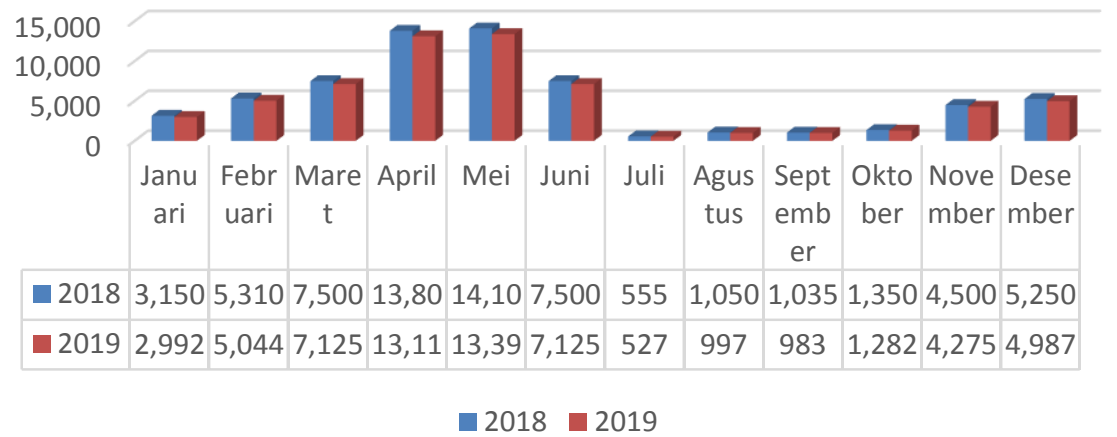

Gambar 6. Jumlah Pengunjung

Sumber: Penulis, 2020

Tabel 3. Daftar Kegiatan Citra Raya World of Wonder

\begin{tabular}{|c|c|c|c|c|c|c|}
\hline \multirow[t]{2}{*}{ Bulan } & \multicolumn{3}{|c|}{ Tahun 2018} & \multicolumn{3}{|c|}{ Tahun 2019} \\
\hline & Event & Masa Libur & Promosi & Event & $\begin{array}{l}\text { Masa } \\
\text { Libur }\end{array}$ & Promosi \\
\hline Januari & & Tahun Baru & & & & $\begin{array}{l}\text { Promo keluarga } \\
\text { (min. } \\
\text { Pembelian) }\end{array}$ \\
\hline Februari & $\begin{array}{l}\text { Pertunjuka } \\
\text { n Barongsai } \\
\& \text { Dragon } \\
\text { Dance }\end{array}$ & Tahun Baru Imlek & & $\begin{array}{l}\text { Pertunjuka } \\
\text { n Barongsai } \\
\text { \& Dragon } \\
\text { Dance }\end{array}$ & & \\
\hline Maret & & $\begin{array}{l}\text { Hari Raya Nyepi } \\
\text { Wafat Isa Al } \\
\text { Masih }\end{array}$ & $\begin{array}{l}\text { Potongan harga } \\
\text { pada jam- jam }\end{array}$ & & & \\
\hline April & & $\begin{array}{l}\text { Isra Miraj Nabi } \\
\text { Muhammad SAW }\end{array}$ & tertentu & & & Promo Pemilu \\
\hline
\end{tabular}




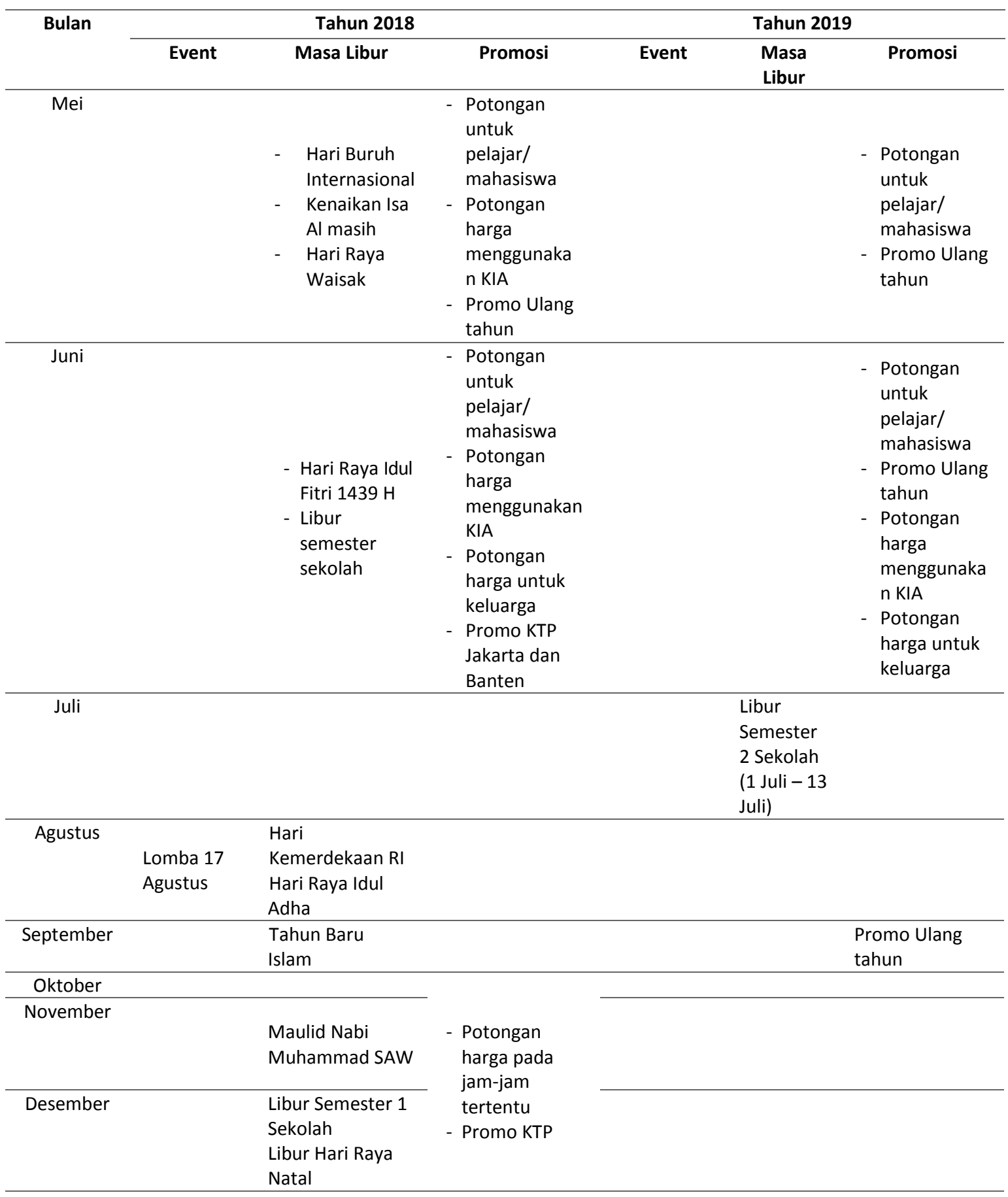

Sumber: Hasil olahan penulis, 2020

Berdasarkan pada grafik dan tabel diatas dapat dilihat bahwa jumlah pengunjung di Citra Raya World of Wonder pada tahun 2019 mengalami penurunan dari tahun sebelumnya, hal ini dikarenakan masih kurangnya promosi yang ditawarkan oleh pihak pengelola serta masih kurang nya event-event yang dilakukan pada bulan-bulan tertentu. Berkaitan dengan masa libur juga pihak pengelola melakukan promosi besar, misalnya seperti pada bulan juni terjadi kenaikan jumlah pengunjung yang tinggi dikarenakan terdapat musim libur semester sekolah dan hari raya idul fitri. Pada hal ini perlu dilakukan improvement peningkatan pengunjung pada bulanbulan yang masih jauh dari target jumlah pengunjung. 


\section{Analisis Best Practice}

Analisis ini berguna untuk mengetahui bagaimana strategi meningkatkan jumlah pengunjung terkait dengan objek wisata yang serupa dengan objek penelitian. Berikut ini merupakan beberapa informasi mengenai strategi dan aspek dalam meningkatkan jumlah pengunjung pada wisata serupa dengan tujuan untuk mengetahui posisi objek studi terhadap objek wisata lainnya. Objek wisata dengan konsep Theme Park yang dengan objek studi adalah Jungle Land Adventure Theme Park yang berlokasi di Sentul, Kabupaten Bogor, Jawa Barat dan Dunia Fantasi yang berlokasi di Ancol, Kota Jakarta Utara, DKI Jakarta.

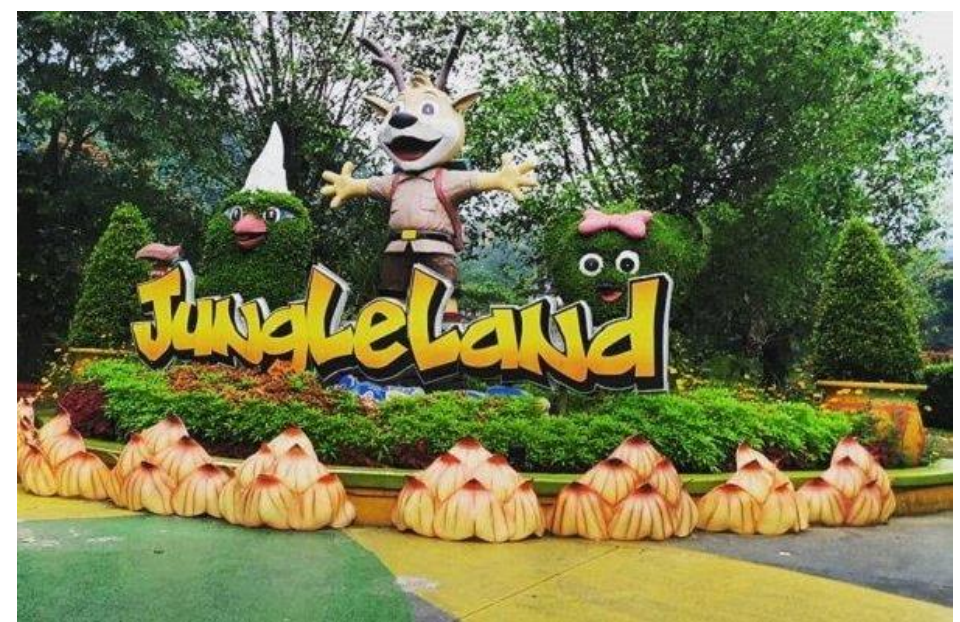

Gambar 7. Jungle Land Adventure Theme Park Sumber: Survey Lapangan, 2020

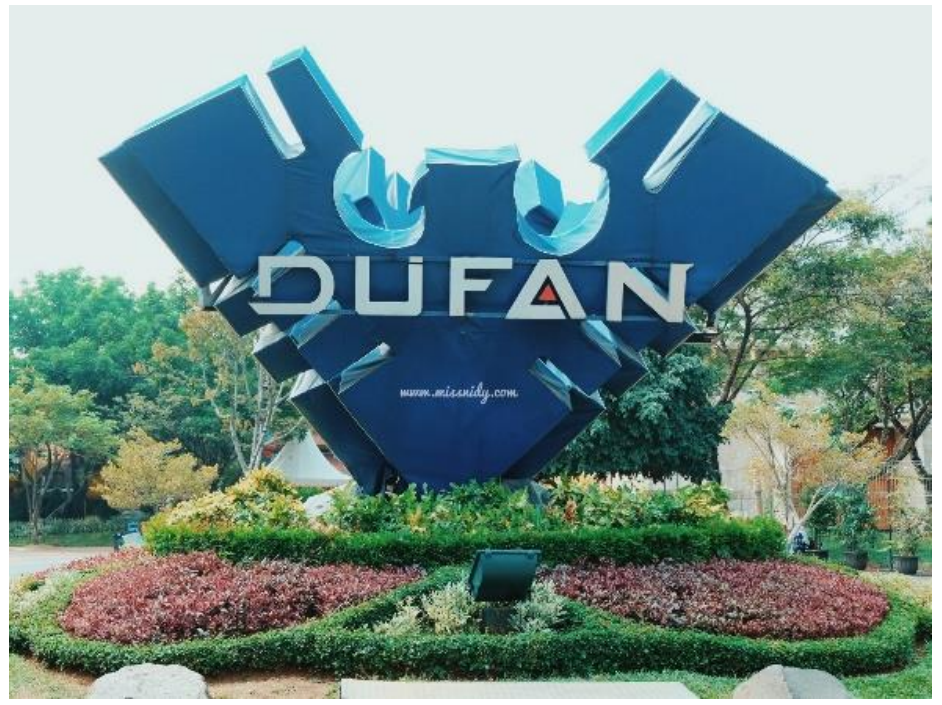

Gambar 8. Dunia Fantasi

Sumber : Instagram @infodufan, 2020

Jungle Land Adventure Theme Park dan Dunia Fantasi memiliki konsep wisata yang sama dengan objek studi. Sehingga jika dilihat berdasarkan aspek-aspek yang ada bahwa beberapa aspekaspek tersebut dapat menjadi sebuah contoh atau kajian terhadap objek studi dengan tujuan untuk mengetahui kelebihan dan kekurangan di objek studi pada saat ini. Sebagai kajian untuk objek studi yang dapat dicontoh dari Jungle Land adalah kegiatan promosi yang sudah dilakukan Jungle Land serta pemeliharaan fasilitas, sarana, dan prasarana yang dilakukan dengan rutin dan konsisten. Untuk Dunia Fantasi sendiri yang dapat menjadi kajian untuk objek studi adalah pengawasan yang cukup ketat dalam bidang pemeliharaan wahana permainan yang ada demi menjaga keselamatan dan kenyamanan pengunjung yang berwisata serta daya tarik dan inovasi 
yang selalu dilakukan oleh Dunia fantasi. Key success untuk menjadi acuan yang dapat diterapkan pada objek studi peneliti ialah:

a. Research, pihak pengelola dapat melakukan penelitian yang jelas dan relevan berdasarkan permintaan pasar bagimana cara meningkatkan daya tarik pasar itu sendiri.

b. Product and Vision, terus melakukan dan mengembangkan inovasi-inovasi yang dapat menambah daya tarik pengujung

c. Harga, kesesuaian harga disesuaikan dengan pasar yang ada disekitar serta disesuaikan dengan wahana dan fasilitas yang disediakan.

d. Manjemen, pihak pengelola harus mengatur semua mengenai pengelolaan lapangan seperti front office, ticketing, checker, kebersihan, operasional dan servis, keamanan

e. Promosi, pada kegiatan ini pengelola dapat terus melakukan kegiatan promosi yang diperlukan untuk membangun kesadaran pada produk serta mendorong pengunjung untuk terus menerus melakukan kunjungan berulang.

f. Reinvestasi, pihak pengelola dapat melakukan reinvestasi pada wahana maupun mengadakan event-event baru untuk menjadi daya tarik kepada para pengunjung, hal ini dapat dilakukan secara teratur untuk memastikan kunjungan berulang.

\section{Analisis Persepsi Pengunjung}

Berdasarkan hasil penyebaran kuesioner pada 100 responden terdapat hal-hal yang perlu ditambahkan, dipertahankan maupun dikembangkan pada lokasi objek studi diantaranya dijelaskan dalam Tabel 3 berikut.

Tabel 3. Hal-hal yang perlu di tambahkan maupun dikembangkan pada

Citra Raya World of Wonder

\begin{tabular}{cl}
\hline No. & \multicolumn{1}{c}{ Yang Perlu Ditambahkan, Dipertahankan maupun dikembangkan } \\
\hline $\mathbf{1}$ & ATM \\
\hline $\mathbf{2}$ & $\begin{array}{l}\text { Fasilitas keamanan di lokasi objek wisata ( Asuransi jiwa, Keterserdiaan staff keamanan dalam } \\
\text { area, safety tools disetiap wahana, peringatan) }\end{array}$ \\
\hline $\mathbf{3}$ & Perlu adanya pendingin di luar ruangan \\
\hline $\mathbf{5}$ & Perlu adanya berupa mascot di Citra Raya World of Wonder \\
\hline $\mathbf{6}$ & $\begin{array}{l}\text { Perlu adanya inovasi pada Theme Park Citra Raya World of Wonder untuk mengikuti trend dari } \\
\text { waktu ke waktu }\end{array}$ \\
\hline $\mathbf{7}$ & Perlu adanya penambahan wahana permainan di setiap kelompok wahana \\
\hline $\mathbf{8}$ & Perlu adanya perbaikan wahana pada wahana yang sudah kurang diminati dan terlihat rusak \\
\hline Sumber: Hasil Olahan Penulis, 2020
\end{tabular}

Pada analisis ini akan dikembangkan lagi pada diagram kartesius untuk mengetahui posisi dari tiap-tiap komponen dalam aspek yang berada pada kuadran yang berbeda, sehingg nantinya akan diketahui faktor apa yang perlu diprioritas terlebih dahulu. Gambar 9 berikut merupakan hasil diagram kartesius. 


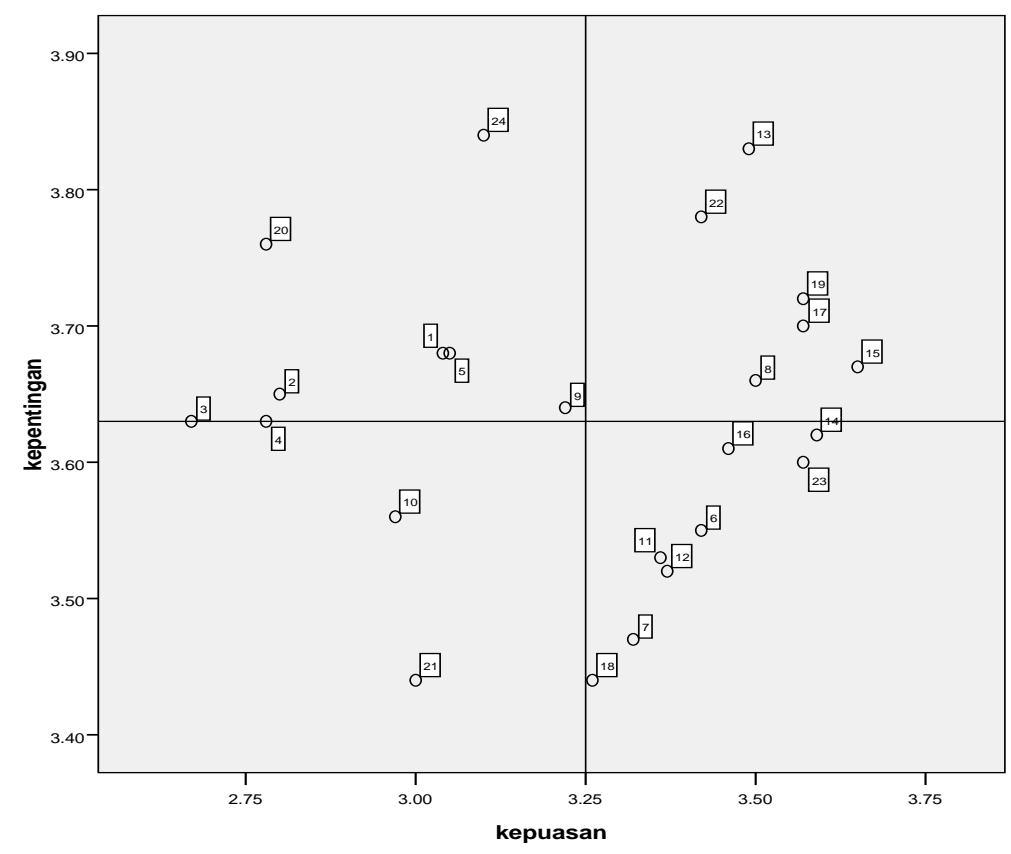

Gambar 9. Diagram Kartesius Pengunjung Citra Raya World of Wonder Sumber: Hasil olahan penulis, 2020

Tabel 4. Kuadram Diagran Kartesius

\begin{tabular}{ccccc} 
No. & $\begin{array}{c}\text { Kuadran I } \\
\text { (Diperhatikan) }\end{array}$ & $\begin{array}{c}\text { Kuadran II } \\
\text { (Dipertahankan) }\end{array}$ & $\begin{array}{c}\text { Kuadran III } \\
\text { (Diabaikan) }\end{array}$ & $\begin{array}{c}\text { Kuadran IV } \\
\text { (Tidak perlu } \\
\text { diperhatikan }\end{array}$ \\
\hline $\mathbf{1}$ & $\begin{array}{c}\text { petunjuk arah menuju } \\
\text { Objek Studi }\end{array}$ & Ruang P3K & Wahana permainan & Sarana beribadah \\
\hline $\mathbf{2}$ & $\begin{array}{c}\text { Transportasi umum } \\
\text { menuju Objek Studi }\end{array}$ & $\begin{array}{c}\text { papan petunjuk } \\
\text { wahana }\end{array}$ & petugas parkir & $\begin{array}{c}\text { Ketersediaan wahana } \\
\text { keluarga }\end{array}$ \\
\hline $\mathbf{3}$ & $\begin{array}{c}\text { Kedekatan dengan } \\
\text { sarana transportasi }\end{array}$ & & Sistem antri loket & Ketersediaan petugas \\
pusat informasi
\end{tabular}

Sumber: Penulis, 2020

\section{KESIMPULAN DAN SARAN}

\section{Kesimpulan}

Berdasarkan hasil penelitian ini dapat ditarik beberapa kesimpulan mengenai Citra Raya World of Wonder, dimana Citra Raya World of Wonder merupakan satu-satunya objek wisata theme park di Kabupaten Tangerang dengan luas 4,3 Hektar. Berdasarkan hasil penelitian Citra Raya World of Wonder memiliki potensi yang sangat besar dikarenakan memiliki aksesibilitas yang 
baik, namun hanya saja masih kurangnya ketersediaan transportasi umum dengan baik. Jika dilihat secara keseluruhan Citra Raya World of Wonder memilki kondisi bangunan yang baik dan layak. Hanya saja, masih kurangnya promosi dan daya tarik yang ditawarkan oleh Citra Raya World of Wonder sehingga pengetahuan pengunjung akan tempat tersebut masih kurang.

\section{Saran}

Dalam beberapa tinjauan dan analisis yang ada maka penulis akan memberikan saran berupa usulan strategi untuk meningkatkan jumlah pengunjung, diantaranya adalah :

\section{a. Promo Media Sosial:}

- Menggunakan jasa influencer dalam membantu mempromosikan dan menjelaskan daya tarik dari Citra Raya World of Wonder melalui media sosial (youtube, Instagram, dll). Hal ini akan menjadi informasi tambahan bagi para penonton yang ingin berwisata

- Diperlukannya promosi berupa penyebaran e-brosur yang dapat disesuaikan pada harihari tertentu

\section{b. Potongan Harga}

- Lokasi objek studi yang dekat dengan fasilitas pendidikan, menjadi suatu potensi untuk pengelola World of Wonder membuat paket hemat yang ditujukkan kepada sekolahsekolah berupa paket tur pelajar

- Melakukan kerjasama dengan pihak biro travel dengan penawaran harga yang tepat

c. Peningkatan Kualitas

- Diperlukannya penambahan petunjuk arah dan infromasi menuju World of Wonder agar pengunjung dapat mudah mengunjungi World of Wonder

- Perlu adanya penelitian mendalam mengenai wahana yang dapat membuat pengunjung melakukan kunjungan berulang

- Berdasarkan hasil best practice, World of Wonder perlu adanya keunikan berupa mascot yang unik agar dapat menjadi daya tarik pengunjung pada saat event atau parade yang menarik pengunjung.

Pihak pengelola World of Wonder diharapkan sering mengadakan event-event yang bertujuan untuk menghibur pengunjung seperti terdapat musik-musik atau mengundang artis-artis ternama, sedangkan untuk anak-anak pihak dapat pengelola menyediakan badut-badut untuk menghibur anak-anak yang sedang bermain, sehingga hal ini membuat pengunjung merasa betah serta menjadi salah satu daya tarik dari pengunjung itu sendiri

\section{REFERENSI}

Assauri, S. (1987). Manajemen Pemasaran. Jakarta Utara: CV Rajawali.

Chandra, F. T. (2005). Service Quality Satisfaction. Surabaya.

David, F. R., (2006). Strategic Management:Manajemen Strategis Konsep. Jakarta: Salemba Empat.

Douglass, R. (1982). Forest Recreation. USA: Pergamon Press.

Ho, P. (2014). Theme Parks and Attraction. The New American City and the End of Public Space. Lawson, M. B.-B. (1997). Tourism and Recreation Development.

Miles. R.E., dan Snow. C. (1978), Organizational Strategy, Structure, and Process, New Yorf, NY: McGraw-Hill.

Personal, S., \& Education, H. (2013). Tourism and Hospitality Studies. Introduction to Tourism.

Phillips, R. (2009). An Introduction to Community Development. Routledge.

Sorkin, M. (1992). A Variation on Theme Park. The New American City and The End of Public Space.

W, R. G. (2004). Manajemen Edisi ketujuh Jilis 2. Jakarta: Erlangga.

Yoeti, A. (1985). Pengatar Ilmu Pariwisata 
Pikkemaat, B., \& Schuckert, M. (2007). Success factors of theme parks-An exploration study. Turizam: međunarodni znanstveno-stručni časopis, 55(2), 197-208. 